
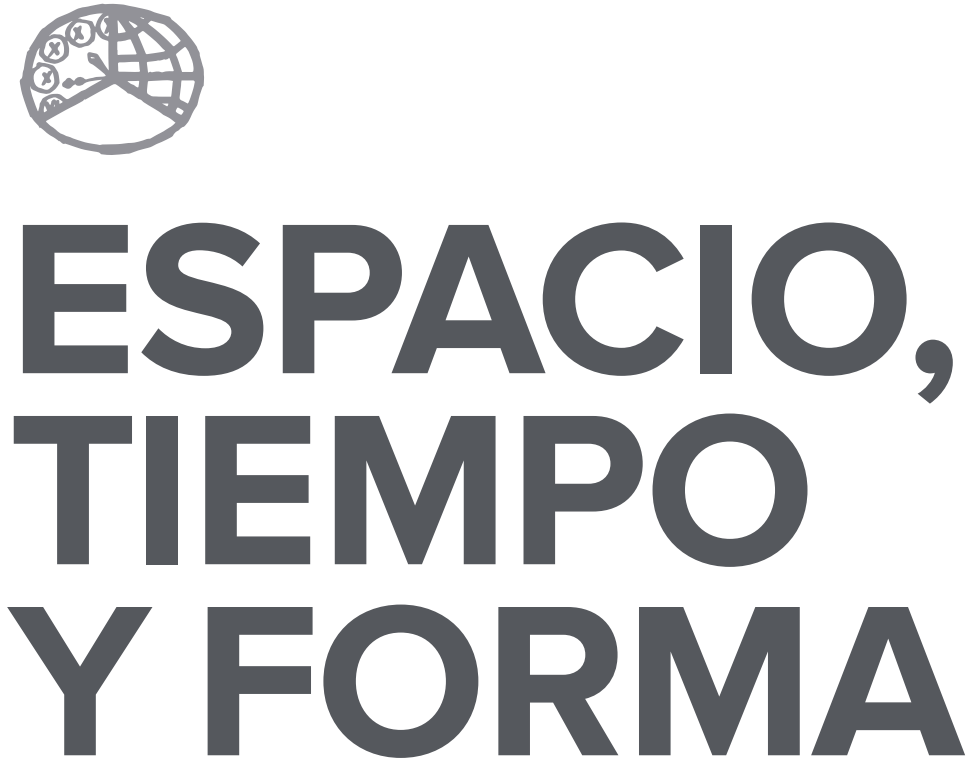

AÑO 2020

ISSN 0214-9745

E-ISSN 2340-1362

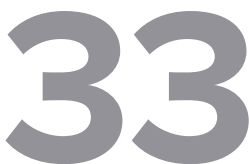

SERIE III HISTORIA MEDIEVAL

REVISTA DE LA FACULTAD DE GEOGRAFÍA E HISTORIA 



\section{ARTÍCULOS · ARTICLES}





\title{
EL CULTIVO Y PROCESADO \\ DEL LINO EN EL REINO DE \\ VALENCIA (SS. XIII-XVII)
}

\section{THE PRODUCTION OF LINEN IN THE KINGDOM OF VALENCIA (THIRTEENTH TO SEVENTEENTH CENTURIES)}

\author{
Frederic Aparisi Romero ${ }^{1}$
}

Recepción: 2019/07/01 · Comunicación de observaciones de evaluadores: 2019/10/14 · Aceptación: 2020/03/12

DOI: http://dx.doi.org/10.5944/etfiii.33.2020.25181

\section{Resumen ${ }^{2}$}

El presente trabajo aborda la producción de lino en el reino de Valencia desde la conquista cristiana hasta la expulsión de los moriscos. Es desde esta perspectiva que se cuestiona la pretendida especialización de las familias musulmanas de dicho territorio en el cultivo e hilado del lino. También se hace hincapié en la participación de las elites rurales en este ámbito productivo. Para acabar, en el estudio se plantea hasta qué punto se puede considerar esta producción como una industria rural en la medida que no hubo especialización productiva ni tampoco participación del capital comercial. Los protocolos notariales, los registros del justicia así como las cartas de población ya editadas son las principales fuentes documentales que sustentan esta investigación.

\section{Palabras clave}

Lino; campesinado musulmán; elites rurales; historia agraria; moriscos; País Valenciano.

1. Investigador postdoctoral 'Juan de la Cierva-formación'. Universitat de Lleida. C.e.: frederic.aparisi@icloud.com

2. El presente trabajo se inserta en el proyecto dirigido por Pere Benito HAR 2016-80298-P: Mercados y comercialización de vituallas en el Mediterráneo Occidental (siglos XIV-XV). Factores e indicadores de desarrollo e integración regional y suprarregional. Ministerio de Ciencia, Innoación y Universidades. Abreviaturas de archivo utilizadas: ACCV = Archivo del colegio del Corpus Christi de Valencia; AMA= Arxiu Municipal d'Alcoi; ARV = Arxiu del regne de València; $s$. = sueldos; $d$. = dineros. 


\begin{abstract}
This paper is concerned with linen production in the kingdom of Valencia from the Christian conquest to the expulsion of the Moriscos in the seventeenth century. From this perspective we will question the supposed specialization of Muslim families of this territory in the production and spinning of linen. Moreover, this study specifically examines the participation of affluent Christian families in this sector. Finally, the article discusses to what extent this production should be classified as a specifically rural economic sector. The notarial protocols, judicial registers as well as previously published population charters are the main documentary sources on which we base our research.

\section{Keywords}

Linen; Muslim Peasantry; Rural Elites; Agrarian History; Moriscos; Valencian Country.
\end{abstract}




\section{INTRODUCCIÓN}

La edad media es el período de esplendor de las fibras textiles de origen animal, particularmente de la lana y, ya a partir del siglo XV, de la seda. Un lugar subsidiario ocupan aquellas fibras de origen vegetal como el lino o el esparto, pero también el cáñamo y el algodón. Y ello a pesar de la gran cantidad de prendas que para el individuo y para la casa eran confeccionados con estas materias, como demuestran para el caso valenciano los inventarios de bienes registrados por los notarios y los escribanos de la Corte del justicia.

La omnipresencia de los tejidos de lino y estopa contrasta con las relativamente escasas referencias documentales que tenemos acerca de su producción y su cultivo. El desarrollo de otras fibras, particularmente la lana y, posteriormente, la seda, han dejado una impronta más intensa en la documentación y en la memoria colectiva. Ahora bien, gracias a la combinación de distintas tipologías documentales -cartas de población, arrendamientos de alquerías, inventarios de bienes y reconocimientos de deuda- podemos tratar de definir las características de este sector a lo largo de la edad media y el primer siglo de época moderna.

El lino, como el esparto o la morera, forma parte de la denominada agricultura industrial o textil. Se trata de cultivos que no iban destinados a la alimentación, sino que para su aprovechamiento exigían un proceso de transformación previo. En algunos casos, esta fase de preparación de la materia prima dio lugar a una verdadera industria como en el caso de la caña de azúcar, el carbón, el cuero o la lana. Sin embargo, convendría preguntarse hasta qué punto el hilado del lino en el reino de Valencia puede considerarse una industria rural, máxime cuando la producción de paños de este tejido fue más bien de ámbito doméstico a lo largo de la baja edad media y hasta la expulsión de los moriscos. En este trabajo predomina la perspectiva de larga duración y la visión de conjunto, más que las coyunturas y las particularidades comarcales. Por ello, se pretende trazar las directrices básicas de un sector, el del lino, poco conocido sobre todo en su fase inicial, desde el cultivo de la planta hasta el hilado de la fibra.

\section{EL PROCESO DE OBTENCIÓN}

De lino existen diversas variedades si bien es cierto que para la obtención de fibras textiles se utilizaban principalmente dos, la vulgar y la bayal. La primera de ellas se sembraba en primavera y se recolectaba en los meses de junio y julio. Por su parte, el lino bayal se sembraba a finales de septiembre para ser recogido tres 
meses después. ${ }^{3}$ Sin embargo, hay que decir que, en general, la documentación valenciana, tanto en cartas de población como en inventarios de bienes, no suele especificar las variedades cultivadas, refiriéndose al lino siempre de forma genérica. ${ }^{4}$

Después de haber recolectado la planta, se retiraban las hojas y los granos de los tallos, que eran tratados a fin de romper la corteza protectora y reblandecer las fibras. Para ello, primero, eran sumergidos en balsas o aprovechando el mismo lecho de los cursos de agua y, posteriormente, se procedía a su cocción. Tras unos días secadas al sol, comenzaba la fase de espadar y picar, que consistía en golpear el lino a fin de separar las fibras del tamo. Una vez llevado a cabo este proceso, se procedía al rastrillado de las fibras de donde se obtenía finalmente el lino, por un lado, y, por otro, la estopa. Mientras que el lino estaba listo ya para su hilado, la estopa exigía un nuevo proceso de cocción para, una vez secada, ser hilada.

El hilado del lino y la estopa se realizaba mediante el empleo del huso y del torno de hilar. En este sentido, conviene apuntar la posibilidad de que, si bien es cierto que los inventarios de bienes que constatan la presencia de tornos siempre especifican que se trata de torn de filar llana, no hay que descartar la posibilidad de que éstos también se hicieran servir para el hilado del lino puesto que la técnica no era diferente al de la lana. Las madejas producidas con el torno debían todavía experimentar un proceso de curación antes de ser utilizadas en la confección de paños.

Dado el largo proceso de transformación del lino desde la planta recolectada hasta la obtención del hilo no es de extrañar que la documentación, particularmente en los inventarios de bienes, se especifique el estado o fase de tratamiento en que se encontraba el lino. Así, el que no había sido curado aparece como lli cru, pero también, como veremos, documentamos el macerado -amerat-, cocido -cuit-o lli picat.

Hay que señalar que de la planta se podían obtener otros recursos, además de las fibras del tallo, si bien estos otros usos eran claramente secundarios. Concretamente, los granos eran utilizados no solamente como simiente para futuras cosechas, sino que, en caso de necesidad, podían ser panificados o, tras la molienda, obtener aceites que se hacían servir en la alimentación, pero también para usos medicinales. Pero sobre todo ello, hay que señalarlo, las referencias al

3. Córdoba, Ricardo: La industria medieval de Córdoba. Córdoba, Caja Provincial de Ahorros, 1990, p. 85-86. NAVARRO, German: Industria y artesanado en Valencia, 1450-1525: las manufacturas de seda, lino cáñamo y algodón, (Tesis doctoral), Universitat de València, 1995, p. 309.

4. Excepcionalmente topamos con alguna referencia aislada. Así, por ejemplo, el campesino de Xàtiva Bartomeu Miquel había cultivado lino vulgar o, como consta en la documentación, stival. En el momento de su muerte se hallaron 142 maços de li stival guardados en dos grandes tinajas. ACCV, Protocols, 23.173 (7-V-1448). También en el arrendamiento de Vilamarxant de 1445 -a unos $30 \mathrm{~km}$ de Valencia- también se hace referencia al lino stival e ivernesch Febrer Romaguera, Manuel (ed.): Les aljames mudèjars valencianes en el segle XV. Valencia, Publicacions de la Universitat de València, 2006, p. 218

5. CóRdoba, Ricardo: La industria medieval..., pp. 90-94. Córdoba, Ricardo: «Industria y artesanía rural en la Corona de Castilla a fines de la Edad Media» en NAVARro, German y VILLANUeVA, Concepción: Industrias y mercados rurales en los reinos hispánicos (siglos XIII-XV). Murcia, Sociedad Española de Estudios Medievales, 2017, p. 53. 
respecto son escasísimas. Solamente he podido constatar el caso de Buñol en cuya carta de poblamiento de 1308 se especifica «que no pagen deçmo de sement de lino». Como bien explica Manel Pastor, esta exención no puede referirse a la reserva de simiente, sino que tiene que ver con los usos secundarios del grano que ya hemos apuntado. ${ }^{6}$

\section{EL CULTIVO Y PROCESADO DEL LINO, ¿UNA ESPECIALIDAD MUDÉJAR?}

\section{II.1. EL TRABAJO DEL LINO ENTRE EL CAMPESINADO MUSULMÁN}

Tradicionalmente, se ha presentado el procesado del lino en tierras valencianas como una especialidad del campesinado mudéjar heredada de sus ancestros que habría sido aprovechada por los señores feudales tras la conquista cristiana. Y es cierto que, si examinamos los tratados de agronomía y los libros de viajes musulmanes, constatamos la presencia de este cultivo en tierras valencianas en época islámica. ${ }^{7}$ Concretamente, en el siglo XII diversos autores mencionan el lino producido en el Sharq al-Andalus. El granadino Ibn Galib destaca el lino de la kura de Valencia, mientras que al-Idrissí menciona de forma específica los paños elaborados en Bocairent. ${ }^{8}$ Este núcleo del interior de las comarcas centrales valencianas se convirtió en un centro de cultivo del lino y confección de paños. Asimismo, también parece ser que se elaboraban distintos materiales para el calafateado y las velas de los navíos que se construían en la madina de Denia, en la costa meridional del Sharq. ${ }^{9}$

Sin embargo, con independencia de este desarrollo del sector del lino, hay que tener en cuenta que ya en época romana se documentan importantes centros productores en la fachada mediterránea de la península Ibérica. ${ }^{10}$ A modo de ejemplo cabe mencionar la villa romana excavada en 2004 en l'Ėnova, cerca de Xátiva. Se trataba de una villa dedicada al cultivo y transformación del lino. ${ }^{\text {II }}$ Y no es este el único caso. Por las mismas fechas se halló en Gandia, en la partida de l'alqueria Rubio, otra villa de época visigoda dotada de estructuras para el tratado

6. PASTOR, Manel: Les senyories valencianes dels comtes d'Urgell. Les baronies de Bunyol, Xiva i Xestalgar entre el 1238 i el 1327: renda i jurisdicció, (Tesis doctoral inédita), Universitat de València, 2015, pp. 419-420 y documento 21.

7. BOLENS, Lucien: Agronomes andalous du moyen âge. París, Droz, 1981.

8. LAGARdere, Vincent: «(1991). Culture et industrie du lin en al-Andalus», Studia Islamica, LXXIV, (1991), pp. 143165, concretamente p. 145.

9. Vallvé Bermejo, Joaquín: «La industria en al-Ándalus», Al-Qantara, l (1980), pp. 209-241, concretamente p. 230.

10. Lombard, Maurice: Les textiles dans le monde musulman VII-XII siècle. París, Mounton, 1978, p. 51.

11. Albiach Descals, Rosa y Madaria, José Luis: La villa de Cornelius. Valencia, 2006. 
del lino. ${ }^{\mathrm{I2}}$ Por otra parte, igual que en las tierras del sharq al-Andalus, también en los territorios de Aragón y Cataluña los campesinos cristianos de los siglos XII y XIII cultivaban lino y elaboraban paños con esta fibra. ${ }^{13}$ No se puede afirmar, por tanto, que este cultivo y su procesado posterior fueran introducidos en la península por los musulmanes ni que fueran éstos los únicos productores.

Tras la conquista y colonización cristiana del Sarq al-Andalus en el siglo XIII, el lino, como la mayor parte de cultivos, fue sometido a la partición de la cosecha, la cual normalmente oscilaba entre I/3 y i/Io. La tributación difería según se trataba de vasallos cristianos o musulmanes, siendo más lesiva -incluso un 50\% más- para éstos últimos. ${ }^{\mathrm{I}}$ Lo que sí era común al campesinado cristiano y musulmán era la obligación de satisfacer los pertinentes tributos eclesiásticos, el diezmo y la primicia. ${ }^{15}$ También tenían que entregar el lino de la partición picat et amerat y conducirlo a la residencia señorial. Como ejemplo, en Xestalgar, en la comarca de los Serranos, según un documento de 1308, cada casa «debe adaguar e maxar e espadar el lino que toca al senyor, según que dará cada moro de so collita e levar-lo a Valencia cada uno». ${ }^{16}$ Más al sur, en Alfafara, alquería próxima a la villa de Bocairent, se especificaba que el lli se parteix picat et amerat, la quarta part al senyor et les tres parts al laurador. ${ }^{17}$

Aunque de forma muy esporádica, es posible constatar la venta de este lino más o menos ya preparado procedente del pago de rentas a través de los protocolos notariales. Así, por ejemplo, Amet Alcannar, de apodo Almadioch, de la morería de Onda, y Abdulamen Abixenci, de la alquería cercana de Veo, reconocieron deber al vicario de dicha villa, Jaume Vives, 347 s. de preu del lli que han comprat de la premécia e dels delmes de la part peranyent al bisbe en la dita vila, a rahó de VI sous VII diners lo feix. ${ }^{\mathrm{I}}$

Pero la partición de la cosecha del lino afectaba solamente a aquellos vasallos que lo cultivaran, como es obvio. ${ }^{19}$ Lo que sí era una imposición presente en la mayor parte de los señoríos de musulmanes era la obligación de satisfacer una cantidad determinada -una o dos libras (de 358 gramos cada una) - de lino ya hilada y, a veces, también de estopa. Esta obligación de filar lli debía estar presente ya en las

12. AlAPONT, Llorenç: «El mundo funerario en el limes visigodo-bizantino: el territorio valenciano», Gausac. Contextos funeraris a la Mediterrània nord-occidental, 34-35, (2009), pp. 145-158.

13. ANDRÉS VALERO, Sebastián: «El campesinado en Aragón en el reinado de Jaime I (1213-1276)» en SARASA, Esteban: La sociedad en Aragón y Cataluña en el reinado de Jaime I (1213-1276). Zaragoza, Institución Fernando el Católico, 2009, p. 239. BeNITO, Pere: Senyoria de la terra i tinença pagesa al comtat de Barcelona (segles XI-XIII). Barcelona, CSIC, 2003, p. 353

14. En Vilamarxant, partexen los moros al quint e los christians al dehé e an-lo a donar amerat e picat. Puntualmente, si la tierra era de secano, la partición podía ser inferior. En Alcàsser, en la Horta de Valencia, en 1417, la producción en las tierras de regadío tributaba al cuarto pero descendía hasta la l/11 parte de la cosecha en el secano. Febrer RomaGUERA, Manuel (ed.): Les aljames mudèjars..., p. 218 y p. 160, respectivamente.

15. VICIANO, Pau: Els peus que calciguen la terra. Els llauradors del País Valencià a la fi de l'edat mitjana. Valencia, Publicacions de la Universitat de València, 2012, pp. 53-72.

16. PASTOR, Manel: Les senyories valencianes..., p. 397.

17. ARV, Reial Patrimoni, Llibre 1, f. 216 (22/9/1416). Citado por NAVARRO, Joaquín: Bocairent Geografia i historia. Bocairent, Ajuntament, 2004 (Original publicado en 1923), p. 114

18. ApARICI, Joaquím: «Capilaridad de la manufactura textil en la plana de Castelló. El caso de Onda en el siglo XV», Anuario de Estudios Medievales, 40-1, (2010), pp. 181-199, p. 195.

19. Pese a todo, en 1417 en la toma de posesión del lugar de Alcàsser el notario todavía lo precisó en la partición del lino: «una garba de lli, cascú qui'n cull». Febrer Romaguera, Manuel (ed.): Les aljames mudèjars, p. 162. 
capitulaciones de rendición del siglo XIII, aunque no disponemos de referencias directas al respecto. Los indicios son, por el contrario, indirectos, como, por ejemplo, la exención de tener que satisfacer esta carga que obtuvieron algunas aljamas. Tal es el caso del castillo de Bes, situado en la zona interior de Valencia y que incluía lugares como Yátova, Millars o Torís, donde los musulmanes no pagaban "alfarda, ni almagrán, ni gallina (...) ni seyades tenidos filar”. ${ }^{\circ}$ Sin embargo, Enric Guinot ya constató como a partir del siglo XIV esta y el resto de las obligaciones y rentas que debían satisfacer los musulmanes aparecen reflejadas con sumo detalle en los contratos de arrendamiento y contabilidades del señorío. ${ }^{21}$

Esta tendencia se mantuvo en la centuria posterior, aunque las particularidades locales dificultan dar una imagen homogénea. Hubo señores, los que menos, que optaron por la conversión del servicio en una renta fija por casa. Es el caso de los Gascó, señores del Real, Benipeixcar y Beniopa, en la Horta de Gandia, que en I383 arrendaron las rentas señoriales a las aljamas de dichos lugares. Gracias al contrato de arrendamiento sabemos que los Gascó habían renunciado a las filaces, e jornals, e lenya e gallines a cambio de un censo fijo de de $\mathrm{i} 6 \mathrm{~s}$. y $4 \mathrm{~d}$. por casa. ${ }^{22}$ La mayoría de los señores, sin embargo, se limitaron a mantener la obligación de las prestaciones en especie, aunque incluso hubo quién trató de incrementar las exigencias señoriales. Así, en I405 Domingo Ros d’Ursins otorgó una nueva carta de población a los musulmanes de Ribesalbes, Berita y Trutxelles, alquerías del término general de Onda, al norte del país, recordándoles que eran tenguts per casa filar una liura de li cascun any. ${ }^{23}$ Cincuenta años después, los musulmanes de Borriol, alquería próxima a Castelló de la Plana, abandonaban de forma clandestina el núcleo ante la petición de más filaces, gallines, pollastres, jornals que supuestamente eran victigals, nous e inusitats. ${ }^{24}$

En otros casos, como en la alquería de Benilloba, próxima a la villa de Alcoi, en el interior de las comarcas centrales valencianas, los vasallos recibían del señor la materia prima y además recibían un salario por ello que estaba, obviamente, por debajo del precio de mercado. Así, los musulmanes del lugar eran tenguts fer filar per cascuna casa poblada que hi haja dona dos lliures de lli e altra de stopa, emperò, lo senyor deu donar lo lli e la stopa, e deu pagar huyt diners per lliura de lli e quatre de stopa. ${ }^{25}$ En buena lógica, el lino que entregaba el señor a estas mujeres procedía de la misma partición de la cosecha. Sin embargo, no siempre era el señor quien proveía de materia prima. En Uixola, también a escasos kilómetros de Alcoi, cada

20. Guinot, Enric (ed.): Cartes de poblament medievals valencianes, Valencia, Generalitat Valenciana, 1991, pp. 305-306.

21. Guinot, Enric: «Los mudéjares de la Valencia medieval: renta y señorío», Áreas, 14, (1992), pp. 29-47, p. 41.

22. Febrer Romaguera, Manuel (ed.): Les aljames mudèjars..., p. 77.

23. IGUAL, David et al.: «Materias primas y manufacturas textiles en las aljamas rurales valencianas» en VI Simposio Internacional de Mudejarismo. Teruel: Centro de Estudios Mudéjares, 1996, p. 321.

24. Hinojosa, Jose: Los mudéjares. La voz del Islam en la España cristiana. Teruel, Centro de Estudios Mudéjares, 2002, documento 155 .

25. ACCV, Protocols, núm. 27.371 (28-III-1477). 
heredad debía entregar una libra de lino y otra de estopa, pero debían proveerse ellos mismos del lino macerado. Además de esta carga, en caso de que el señor lo solicitara, debían hilar para él a cambio de un salario inferior a los I5 d., en el caso de la libra de lino, y de $9 \mathrm{~d}$. la de estopa. ${ }^{26}$

Finalmente, también documentamos algunos casos donde es la propia aljama la que acordaba con el señor la entrega de una cantidad determinada de lino hilado, siendo ella misma la responsable de llevar a cabo la distribución de la carga entre los miembros de la comunidad. Esto es lo que ocurrió en 1405 en Monòver y Xinosa, donde la aljama se comprometió con el señor a filar cascun any noranta lliures de filaça. ${ }^{27}$ Sin embargo, ello no quiere decir que las noventa casas de la morería -dividida en dos núcleos- participaran del hilado. Muy probablemente los dirigentes de la aljama redistribuyeron después la carga entre los miembros de la comunidad en función de las posibilidades de cada familia.

Como hemos podido ver anteriormente, los musulmanes ya cultivaban lino con anterioridad a la conquista cristiana. Pero solamente algún centro urbano aislado destacó por el volumen y la calidad de la producción. La imposición de entregar al señor lino hilado no respondía, pues, a ninguna especialización productiva de los campesinos musulmanes frente a los cristianos. Nacía de la propia capacidad de los señores para someter a la sociedad vencida con unas condiciones de vasallaje más duras que las que podían imponer a los colonos. ${ }^{28}$ Este requerimiento señorial sería el que acabaría forzando la pretendida especialización mudéjar sin que la producción de lino musulmán limitara el desarrollo del cultivo entre los cristianos.

Las cargas señoriales referidas al lino, como el resto, se mantuvieron a los vasallos moriscos tras las Germanías hasta su expulsión en i609. Un buen ejemplo que atestigua la pervivencia de esta imposición y sobre todo el tratamiento diferenciado de los vasallos cristianos con respecto a los musulmanes es la carta puebla de Benimodo y Carlet concedida en 1520 , a las puertas del estallido de las Germanías. ${ }^{29}$ Entonces, cristianos y musulmanes aunaron esfuerzos para forzar al señor de la baronía a la revisión de las condiciones de vasallaje y negociar otras menos lesivas, ante las demandas abusivas de éste. Y una de las diferencias más significativas se aprecia en lo que respecta a la producción de lino. El pago de la renta sería el mismo que el de otros cultivos. En el caso de los cristianos pagarían diezmo, del cual tomaría el señor la tercera parte, y la primicia en las tierras de regadío y la I/II parte en el secano. Los moriscos, en cambio, debían satisfacer 1/4

26. AMA, Protocols núm. 494 (24-I-1448).

27. Febrer Romaguera, Manuel (ed.): Les aljames mudèjars..., p. 116.

28. Por supuesto, esta diferenciación no se reducía a la producción de lino. Josep Torró ha analizado en detalle esta "renta de la diferencia" -la expresión es suya- haciendo hincapié en el hecho que la exacción señorial no consistía únicamente en la partición de la cosecha sino también en una carga importante de trabajo, puesto que el producto debía entregarse dispuesto para su almacenamiento o su comercialización. TorRó, Josep: «Vivir como cristianos y pagar como moros: genealogía medieval de la servidumbre morisca en el reino de Valencia», Revista de historia moderna: Anales de la Universidad de Alicante, 27 (2009), pp. 11-40.

29. Febrer Romaguera, Manuel (ed.): Les aljames mudèjars..., p. 359-360. 
de la cosecha como partición, con independencia de la calidad de la tierra. Y no sólo esto, sino que les mores de cascun pati de casa o en nom de paga an de filar una lliura de lli o dues de estopa. Además de estas imposiciones generales a todas las familias, otros tres capítulos específicos sobre el lino regulaban los trabajos de aquellos y aquellas que sabían procesarlo. Así, todo aquel que fuera espadador o soliera espadar en la baronía, es decir, tanto el profesional específicamente dedicado a ello como el que lo hacía ocasionalmente, en la baronía estaba obligado a espadar también el lino del señor a razón de 4 s./arroba. Igualmente, les mores que saben rastellar en tota la senyoria, es decir, que no todas sabían hacerlo, debían rastrillar lo lli del senyor a razón de 2 s./arroba, aunque el señor estaba obligado a donar-los almorsar e a mig jorn dinar, e no a sopar. Y, por último, todo aquel que supiera tejer o soliera hacerlo -de nuevo se diferencia entre el trabajador experto y el ocasional- debían tejer para el señor razón de 4 d./alna en el caso del lino y de 3 d./alna de la estopa si bien puntualiza el documento que lo damunt orde de texir han de tenir les fadrines y no les casades..$^{\circ}$ De esta forma, el señor de la baronía de Carlet, que por aquel entonces era Galceran de Castellví, aprovechaba el saber de las musulmanas de sus dominios -de una parte de ellas al menos-para obtener unas rentas en especie que bien podrían servir para su propia casa o bien ser colocadas en el mercado, como hemos podido ver anteriormente.

Ahora bien, no era únicamente a través de las imposiciones feudales como los señores obtenían materia prima hilada. Otro mecanismo mediante el cual accedían a esta era la imposición de penas y castigos a aquellas musulmanas que hubieran cometido algún delito. Valga como ejemplo el caso de las sanciones impuestas por Miquel Joan Ros, señor de la alquería de Daimús, también en la Horta de Gandia. En I553 establecía una pena $20 \mathrm{~s}$. de multa al hombre que insultara a otro con palabras como lladre, cornut o altra qualsevol paraula odiossa. Para las mujeres, en cambio, la pena no era monetaria sino en especie: la que comensarà la qüestió sia encorreguda en pena de dos gallines y de filar dos lliures d'estopa i la que li respondrà sia encorreguda en paguar una galina i de filar una lliura d'estopa. ${ }^{\mathrm{I}}$

Todas estas cargas feudales en especie no condujeron a una especialización productiva de aquellas aljamas que tenían que soportarlas, al menos no necesariamente, como pone de manifiesto el ejemplo anteriormente expuesto de Daimús. Aquí, pese a la obligación de entregar anualmente una libra de lino hilado, y de las penas en libras de estopa a las mujeres, éste no dominó el paisaje agrario ni fue tampoco la dedicación principal de sus vecinos. Tampoco entre las aljamas del interior el lino se convirtió en el cultivo más destacado. Ya he mencionado el caso de Xestalgar, donde el lino tributaba como el resto de los cultivos. En la villa próxima de Buñol, el lino debía satisfacer I/Io -igualmente, como resto de cultivos-y,

30. Una alna equivale a unos $90 \mathrm{~cm}$.

31. Arxiu Històric de la Ciutat de Gandia, B-1.988 (crida del 20 de marzo de 1553). 
por otra parte, «una mana de lino de cada casa, cada anyo en su tiempo».32 En ambos lugares, los cereales y, más aún, el ganado ovino y el arrendamiento de los pastos eran los principales activos económicos locales. ${ }^{33} \mathrm{Y}$ tampoco parece que se desarrollara ningún tipo de especialización en el norte del país. En la villa de Onda, con una morería propia y rodeada de alquerías de población musulmana, en I495, las obligaciones consignadas ante el justicia por lino eran por un valor de 34I s. que sobre el total registrado por la corte solamente representaban el 2,2\%.34

Pero, ¿cuánto llegaban a ingresar los señores valencianos por el lino hilado por sus vasallos? En términos generales, la clave de la rentabilidad de este producto residía en el acceso, a través de la partición de la cosecha, a la materia prima sin coste alguno. A ello habría que añadir que el salario que recibían las mujeres, si es que lo recibían, estaba por debajo del precio de mercado. Así, por ejemplo, en el caso de Benilloba, la libra de lino hilado tenía un coste para su señor de $8 \mathrm{~d}$., aunque en Uixola, a escasos kilómetros, era inferior a I5. El caso más extremo era el de la baronía de Carlet, cuyo señor obtenía en 1520 dicho lino hilado por tan solo 3 d. y la obligación de dar de comer a las mujeres moriscas. En cambio, la misma cantidad trabajada por los cristianos debía pagarse, al menos, en torno a los 20-25 d. 35 Con todo, tampoco hay que sobredimensionar el valor económico de esta exacción. Entre I4I6 y I438 la mencionada alquería de Alfafara formó parte de la villa de Bocairent, razón por la cual el baile de esta villa real era el responsable de gestión financiera de dicho lugar. En I42I las rentas no fueron arrendadas y por ello el baile tuvo que gestionar directamente la recaudación. Así pues, en el conjunto el dret de lli, que integraba también el d'erbes, representaba únicamente el 2,I\% del total, sólo por delante del o,I\% de los luismos, y muy similar al 2,3\% de las regalías. Los ingresos por besantes y los derivados del ejercicio de la justicia eran superiores, un 8 y un $4,3 \%$ respectivamente..$^{36}$

Hasta ahora las referencias al cultivo y sobre todo al hilado del lino que hemos analizado proceden de fuentes que podríamos denominar legislativas, como cartas de población o crides del señor local. Más complicado resulta documentar el trabajo en el ámbito doméstico. Como en el caso del campesinado cristiano, los inventarios de bienes son la tipología documental más pertinente para acceder

32. PASTOR, Manel: Les senyories valencianes..., pp. 106-107.

33. CRUSELLES, Enrique: «Pastos, ganadería ovina y mercado regional de la lana en el reino medieval de Valencia» en Mattone, Antonio y Simbula, Pinuccia: La pastorizia mediterranea. Storia e diritto, secoli XI-XX. Roma, Carocci, 2011.

34. APARICI, Joaquím: «Acudir ante el justicia para formalizar contratos. Los mercados rurales delínepinorte del reino de Valencia (siglo XV)» en NAVARro, German y VILLANUEVA, Concepción: Industrias y mercados rurales en los reinos hispánicos (siglos XIII-XV). Murcia, Sociedad Española de Estudios Medievales, 2017, p. 255.

35. Dicha cifra procede, por un lado, de la cantidad que pagaba el señor de la Uixola a sus vasallos por el hilado de lino al margen de las dos libras de renda feudal que debían entregarle. Por otro lado, en Vinalesa, en la huerta de Valencia, la libra de lino hilado podía pagarse a 3 s. 6 d.s, si bien aquí se trataba de población cristiana. (ACCV, Protocols, núm. 20.075, 30-XI-1500). En cualquier caso, soy consciente de que se trata de cifras dispersas y fragmentarias que exigen precaución a la hora de considerarlas.

36. Mira JODAR, Antonio José: Entre la renta y el impuesto. Fiscalidad, finanzas y crecimiento económico en las villas reales del sur valenciano (siglos XIV-XV). Valencia, Publicacions de la Universitat de València, 2005, p. 34. 
a este tipo de información. Ahora bien, antes que nada, hay que señalar su escasez. No era habitual que un musulmán requiriera la presencia de un notario cristiano para realizar un inventario de sus bienes, por ello resultan tan raro en este tipo de fuentes. La mayor parte de los que han llegado hasta nosotros los documentamos en los libros de la Corte del justicia. Se trata de inventarios de bienes confeccionados a raíz de la denuncia de impago por parte de un cristiano. Por tanto, el listado de bienes se limita a cubrir la cantidad monetaria debida, no un registro completo de la casa.

Hace unos años, Joaquim Aparici publicó un total de 23 inventarios de bienes comprendidos entre I44I y I527 de musulmanes de las morerías de Castelló de la Plana, Onda y Segorbe localizados en los registros del justicia de las respectivas villas. ${ }^{37}$ El amplio período y la geografía del estudio en contraposición con el número de documentos localizados nos ofrece una clara idea de la exigüidad de éstos. Pues bien, de los 23 inventarios solamente 5 incluyen alguna referencia al lino, en su mayoría haces de lino picado o todavía por picar.

Así, de la morería de Castelló de la Plana, Amet Alger i Suleimen Alger tenían, respectivamente, $X X$ fexos de lli poc més o menys, no piquat, y XXXX fexos de lli, no piquat. Unos meses más tarde, de nuevo el justicia embarga a Suleimen una caxa e dos fexos de lli. Ítem, dotze fexos de lli picat. Y aún en el mismo año de 1445 incautan a Amet, junto a otras pertenencias, un munt de fexos de lli amerat e picat..$^{8}$ Las otras dos referencias son más tardías. En I493, en Segorbe, en casa de Abdulasís Xacara se registran, en la entrada, primo, set faixos de lli ben cuyt per piquar. [En] altra part, tres feixos de lli cuyt per piquar, y, en la cocina, hun teler dolent de texir. La última procede de nuevo de Castelló de la Plana. En I495 se hallan en casa de Ali C, alio quatre fexos de li piquat. Finalmente, hay que mencionar un sexto inventario, el de Amet Alfaquinet, de la morería de Segorbe. Este no menciona de forma específica al lino, aunque probablemente de esta fibra sean las dues lliures de fill, poch més o menys recogidas en el inventario. Además, se registran hun pes de spart, hun buch ple de stopa, una roda de torn, hun tornet chiquet, hun peu de debanadores, y todavía hun teler de texir lenc. .39 Ahora bien conviene señalar que en los 6 casos se trata de individuos que proceden de las respectivas morerías de Castellón y de Segorbe, surgidas, como la mayoría del reino de Valencia, bastante después de la conquista para alojar población musulmana que habría de trabajar, en gran medida, en las explotaciones agrícolas de las gentes de la ciudad.

Estos musulmanes no tenían que satisfacer cargas señoriales como la entrega de cantidades de lino hilado como sus correligionarios, aunque no por ello su situación socioeconómica era mucho mejor, sino que se limitaban a pagar una serie

37. ApARICl, Joaquim: «Bienes muebles de mudéjares castellonenses. Siglo XV», Sharq al-Andalus, 19, (2008-2010), pp. 69-90.

38. Respectivamente, documentos 6,8 y 9 del mencionado artículo.

39. Respectivamente, documentos 17,18 y 19 del citado artículo. 
de tributos en moneda al señor del municipio..$^{40}$ En estos casos, la dedicación al lino, tanto a su cultivo como a su posterior procesado e hilado, era el resultado de una elección. Nada que ver con la situación de aquellos musulmanes que estaban sometidos a la pequeña nobleza y al clero, con unas condiciones más exigentes. Para ellos, el trabajo del lino era una exigencia de su señor.

Tras la expulsión de los moriscos, todo este tipo de cargas feudales al margen del pago de los tributos desaparecieron completamente. Si analizamos las cartas pueblas otorgadas por los nobles valencianos a partir de 1609 , las únicas referencias al lino son a propósito de la partición de frutos, que continuaron oscilando entre I/3 y I/ıo de la cosecha, pero en ningún caso se hace mención de la entrega de lino hilado..$^{41}$ Tampoco hay rastro de penas en especie que impliquen la entrega de productos elaborados al señor. Como había sucedido casi cuatrocientos años antes, los señores fueron incapaces de imponer a sus vasallos cristianos cualquier coacción o tipo de trabajo que fuera más allá de la renta feudal y de las regalías. Por tanto, de ser una especialización musulmana-morisca, el lino debería haber desaparecido, como sucedió con el cultivo de la caña de azúcar que se había desarrollado en la Horta de Gandia vinculado a la población andalusí. ${ }^{22}$ Sin embargo, esta planta textil continuó existiendo y, de hecho, todavía experimentó un desarrollo notable en el siglo XVIII. ${ }^{43}$ En definitiva, las cartas de población y los contratos de arrendamiento de señoríos nos permiten conocer el procesado del lino dentro del ámbito musulmán, pero resultan insuficientes a la hora de estudiar la otra esfera productiva, la del campesinado cristiano, que, sin duda, también existió.

\section{II.2. EL TRABAJO DEL LINO ENTRE EL CAMPESINADO CRISTIANO}

Podemos constatar la producción de lino por parte del campesinado cristiano desde el mismo momento de la conquista. Los datos aportados por Josep Torró sobre el terç-delme, un tercio del diezmo que correspondía a la Corona o, por donación de ésta, al señor, para las villas de Borriana, Cullera, Corbera Gandia y en I263 confirma esta presencia, pero con matices interesantes. ${ }^{44}$ De entrada, hay que señalar la absoluta ausencia para las villas de Alzira y de Ontinyent. En Gandia, tiene

40. Se puede observar en la carta de poblamiento de la morería de la villa de Alcoi de 1468, donde no hay referencia a este tipo de cargas. Febrer Romaguera, Manuel (ed.): Les aljames mudèjars..., p. 260.

41. ARDIT, Manuel y GUINOT, Enric (eds.): Cartes de poblament modernes valencianes (XVI-XVIII). Valencia, Publicacions de la Universitat de València, 2015.

42. LA PARRA, Santiago: Los Borja y los moriscos. Repobladores y terratenientes en la Huerta de Gandía tras la expulsión de 1609, Valencia, Institució Alfons el Magnànim, 1992.

43. PIQUeras, Juan: «El fomento de plantas textiles en la España ilustrada. Una visión espacial», Cuadernos de geografía, 50 (1991), pp. 247-262.

44. TORRó, Josep: El naixement d'una colónia. Dominació i resistència a la frontera valenciana (1238-1276). Valencia, Publicacions de la Universitat de València, 2006, p. 144. 
una escasa incidencia, ya que los I5 s. 3 d. recaudados solamente representan 2,7\% del total percibido por el infante Pere, titular de estas villas. En Corbera, el peso no era mucho mayor, del 5,5\%. En Cullera apenas superaba el o,5\% del conjunto de las rentas. Por el contrario, en Borriana, el infante Pere ingresó zoo s. derivados de la producción de lino, cifra que solamente era superada por los cereales $-569 \mathrm{~s}$. por el trigo y 480 por la avena. ¿Cómo explicar estas cantidades tan dispares entre el norte y el centro-sur del reino? La razón principal de esta disparidad está en los ritmos propios de cada región, y de cada villa, en el proceso colonizador. A la altura de 1263, habían transcurrido casi treinta años de la conquista de Borriana pero apenas veinte en el resto de villas mencionadas, diez en el caso de Gandia. En consecuencia, la colonización estaba mucho más consolidada en el norte que no en el sur, donde, todavía en la década posterior se habrían de repartir importantes lotes de tierras. ${ }^{45}$ Por otra parte, conviene tener presente que en la villa de Borriana no existía ya por 1263 población musulmana, sino que esta había sido expulsada anteriormente. Esa producción por valor de $300 \mathrm{~s}$. -que podía llegar a los 900 para el conjunto del diezmo- era netamente cristiana.

Para los siglos posteriores, particularmente a partir de I375, la mayor parte de referencias de que disponemos proceden, no de fuentes fiscales, como en el anterior caso, sino de los protocolos notariales, sobre todo con inventarios de bienes post-mortem, y de las obligaciones ante el justicia local. Estas fuentes reflejan la posesión de lino, en sus distintas fases de transformación, en manos del campesinado cristiano. Sin embargo, esta presencia no es generalizable al conjunto de las familias campesinas. Y es que mientras que en el caso de los labradores musulmanes la producción de lino respondía a un requerimiento señorial, en el caso de los cristianos era el resultado de una elección de la unidad doméstica.

Dentro de las estrategias productivas del campesinado, el autoabastecimiento de los productos básicos - cereales, vino y aceite- ocupaba un lugar primordial. ${ }^{46}$ Estos cultivos no solo ocupaban mayor extensión dentro de la explotación familiar, sino que también las mejores tierras. En este esquema, todo aquello que no fuera susceptible de ser consumido, entiéndase panificable, ocupaba un lugar secundario en la pequeña explotación. Solamente, las explotaciones más grandes, que ya destinaban troços -voz que aparece en la documentación- de tierra a estos cultivos, podían introducir otros con una clara orientación para el mercado como el lino o el azúcar. ${ }^{47}$

45. De hecho, Torró ha llamado la atención sobre las cifras de Ontinyent y Gandia, dado que son particularmente bajas. A su entender, es más que probable que hubiera habido un algún tipo de acuerdo fiscal entre la administración real y los nuevos pobladores a fin de consolidar la colonización. TORRó, Josep: El naixement d'una colónia..., pp. 148-149.

46. Viciano, Pau: Els peus que calciguen la terra. Els llauradors del País Valencià a la fi de l'edat mitjana. Valencia, Publicacions de la Universitat de València, 2012, pp. 163-169).

47. VICIANO, Pau: «Pagesos que innoven. La petita explotació en les transformacions agràries de la fi de l'edat mitjana» en BARCELó, Miquel et al.: El feudalisme comptat i debatut. Formació i expansió del feudalisme català. Valencia, Publicacions de la Universitat de València, 2003. 
Y esto es reseñable desde el mismo momento que se consolida la colonización. En I275, en la heretat del caballero Ximén Pérez de Artieda, situada en el término de Cocentaina, se recolectaron diversas cantidades de cebada, centeno, espelta, habas i in fajos de lino..$^{8}$ A escasa distancia de allí, en Penáguila, otro personaje acomodado, Guillem de Vilanova trabajaba su explotación, una parte de la cual estaba plantada de lino, con mano de obra asalariada. Uno de sus jornaleros donà XVII sous als moros que havien espadat lo li. ${ }^{49}$

La mayor parte de referencias proceden de la baja edad media. Sobre una muestra de 57 inventarios post-mortem confeccionados entre I37I y I498 -si bien 45 de ellos corresponden a la segunda mitad del siglo XV-, en prácticamente el 70\% de ellos documentamos la presencia de reservas de lino, en cualquiera de sus fases de transformación..$^{\circ}$ Conviene recordar que esta agricultura textil era altamente exigente con los suelos y requerían, por tanto, de su mejora con aportes regulares de abono, algo que, de nuevo, solamente los campesinos con más recursos podían afrontar de forma sistemática. ${ }^{51}$ Así pues, dado que no existía la posibilidad de utilizar el lino como alimento, a excepción de alguna variedad con la que se producía la linaza, y de lo agresivo que era para el suelo su cultivo, no debe resultar extraño que fueran los campesinos acomodados quienes eligieran dedicar alguna parcela de su explotación agrícola a esta planta textil.

Un buen ejemplo de ello es el caso de Miquel Segura, vecino del Ràfol de Va1ldigna. ${ }^{52}$ En I39r la explotación agrícola de esta familia estaba compuesta por un total de veinticuatro parcelas de tierra de diversa extensión, diseminadas por el término. De ellas, casi la mitad, diez, correspondían a trigo. Del resto, cinco eran de viñedo, dos plantadas de higueras y dos de olivos. También existían otras tres con cebada, hortalizas, algarrobos, y I era marjal. Finalmente, había «I troç de terra censal en què ha $V$ fanecades, tot sembrat de lli». Dado que no se especifica la extensión de las otras parcelas resulta imposible valorar el peso real del lino en el conjunto de la explotación, pero porcentualmente representaba casi el $4 \%$ de las parcelas frente al trigo y el vino que representaban 4I,6 y el 20,8\% respectivamente. Resulta obvio que el lino, como otros cultivos, tenía un carácter complementario en las estrategias productivas de Miquel Segura.

En el caso de la familia de Nicolau Llobregat de Mislata, núcleo próximo a la ciudad de Valencia, las estrategias productivas giraban igualmente en torno al cereal y el vino. De hecho, no se especifica qué parcela de las 9 ha. que constituían la explotación campesina se dedicaba al lino. Sin embargo, el inventario de bienes

48. Ferragud, Carmel: El naixement d'una vila rural valenciana. Cocentaina, 1245-1304. Valencia, Publicacions de la Universitat de València, 2003, p. 126.

49. Ferragud, Carmel: El naixement d'una vila rural valenciana... p. 123.

50. APARISI, Frederic: Del camp a la ciutat. Les elits rurals valencianes a la baixa edad mitjana, (Tesis doctoral inédita), Universitat de València, 2016, p. 323.

51. APARISI, Frederic: Del camp a la ciutat..., p. 98

52. Archivo Histórico Nacional, Nobleza, Osuna, llig. 1.136 n. 4 (4-l-1391). 
constata la presencia de una cantidad significativa de esta fibra textil en distintas fases de transformación. Así, se inventariaron 7 arrobas de lino de casa, otra de li cru y otra de estopa. Y además I4 libras de fil de lli de casa grosser, es decir, hilo que era ya susceptible de ser utilizado en la confección de paños de lino.53

El caso de los Castrellenes es exactamente el contrario a los expuestos ya que para esta familia de campesinos acomodados residente en su alquería de l'Olleria, situada en la huerta periurbana de Valencia, el lino representaba la principal fuente de ingresos, por delante incluso del trigo. Igualmente, de entre todos los trabajos agrícolas, el procesado del lino era el primero en cuanto a inversión se refiere puesto que exigía más jornales que la recolección del arroz o que la vendimia. De hecho, contaban con su propia bassa per amerar li.54 Desde luego no debía ser extraño el cultivo y el macerado del lino en el entorno inmediato de la ciudad ni tampoco en el espacio de la huerta porque el de los Castrellenes no es un ejemplo aislado. En el momento de su muerte, en la alquería de Bartomeu Ros, otro campesino acomodado que residía en la huerta próxima a la ciudad, se hallaron dos libras de li rastellat, un cajón dins lo qual havia un poch de li e d'estopa per rastellar, un peine de rastellar li así como 42I kg de li spadat y dos cahices (402 l.) de simiente de lino.55

También en el interior de las murallas de la ciudad documentamos ejemplos de campesinos acomodados dedicados al cultivo e hilado del lino. Es el caso del anteriormente citado Bartomeu Miquel, de la ciudad de Xàtiva, en cuya casa se hallaron I42 maços de lino estival depositados en dos grandes tinajas..$^{56}$ En otras ocasiones, el inventario de bienes no constata la presencia del lino, pero sí que se hallan los instrumentos para su preparación. A la muerte de Sibila su marido, Lluís Blasco, realizó el inventario de los objetos que había en el interior de su casa de Borriana. Aquí, además de dos rastells de rastellar li, el notario registró set alnes (6,3 m.) de tela de drap de lli y de estopa", que podemos aventurar que habían sido elaboradas con materia prima de la propia familia por parte de un tejedor. ${ }^{57}$ Esto es lo que hicieron Joan Espareguera y su mujer Isabel. A la muerte de ésta, Joan reconocía que he donat a teixir fora casa dues teles, la una lli e stopa que son I4 lliures, l'altra de li grocet, de dos sous de filar la liura, en la qual he donat 6 lliures de fil. $5^{8} \mathrm{Y}$ es que la posesión de telares por parte de estas élites rurales era un hecho muy poco frecuente. De los 57 inventarios trabajados entre I37I y I498 solamente uno de ellos contenía hun teler de texir draps de lli, además de dos pintes per al dit teler. El hecho de pertenecer a un platero radicado en una pequeña villa, Llutxent, sugiere que debía ser utilizado por el personal doméstico de la casa, que también debían

53. ACCV, Protocols, núm. 23.024 (12-XII-1502).

54. Garcia-Oliver, Ferran: «Élites campesinas en el entorno de la ciudad de Valencia: los Castrellenes», Studia histórica. Historia medieval, 35-2, (2017), pp. 119-144, p. 131.

55. ARV, Protocols, núm. 1.890 (4-IV-1421).

56. ACCV, Protocols, núm. 21.173 (7-V-1448).

57. Idem, núm. 23.024 (2-XI-1502).

58. Idem, núm. 23.242 (14-III-1495). 
hacerse cargo del torno de hilar seda. ${ }^{59}$ Así pues, el cultivo del lino formó parte de las estrategias productivas del campesinado acomodado valenciano, si bien con un grado de protagonismo en la economía familiar diverso según los casos.

\section{REGULAR LA ACTIVIDAD}

Por lo que a las ordenaciones municipales se refiere, la mayor parte de los Consejos trataron de delimitar las zonas en las que el lino podía ser macerado dentro del término general del municipio y prohibir su procesado dentro los muros de las villas. Conviene señalar que estas disposiciones debían ser observadas tanto por los vecinos del propio municipio como por las gentes que residían en las alquerías diseminadas por el término general de la villa, de población musulmana la mayor parte de ellas.

Así, por ejemplo, en el caso de Alzira en 1372 se establecía que nadie gos amerar li en lo riu de Xúquer, ço és, al cap del pont de Santa Maria de la dita vila en loch on no sia l'aygua corrible, e açò sots pena de cinch sous. ${ }^{60}$ Más al norte, en Vila-real, el Consell estableció a finales del siglo XIV que algú no gos batre ni ventar ni espadar ni estendre lly algú dins los murs ni en los rabals de Vila-real, sots pena de 3 sous. ${ }^{6 \mathrm{r}}$

En el caso de la ciudad de Valencia, al menos en el siglo XIV las disposiciones del Consell son bastante escasas y no se refieren al lino en exclusividad sino que incluyen también otras fibras textiles. ${ }^{62}$ La única mención exclusiva tenía que ver no con la producción sino con la compraventa del lino ya hilado, la cual se tenía que realizar en la plaza de la Figuera. ${ }^{63}$ Esta ausencia de referencias en la documentación municipal de la ciudad de Valencia, que continua en el siglo $\mathrm{XV}$, podría ser indicativa de una escasa presencia de este cultivo en la zona de la huerta. Sin embargo, los registros de la corte del justicia constatan la utilización de las acequias más próximas a la ciudad para el lavado de paños de lino, además de otras fibras. ${ }^{64}$ Pero es a través de la documentación notarial donde constatamos con mayor claridad la existencia de balsas para el maceramiento y parcelas plantadas de lino en el entorno inmediato de la ciudad por parte de campesinos acomodados, como hemos visto con anterioridad a propósito de Bartomeu Ros y de los Castrellenes.

59. APARISI, Frederic: Del camp a la ciutat..., p. 323.

60. LAIRON, Aureliano (ed.): Libre de diverses statuts e ordinacions fets per lo consell de la vila de Algezira. Valencia: Publicacions de la Universitat de València, 2001, p. 68.

61. GIL, Vicent (ed.): Ordenances municipals de Vila-real (segles XIV-XVIII). Valencia: Publicacions de la Universitat de València, 2002, documento 246.

62. BORDES, Jose: Desarrollo industrial textil y artesanado en Valencia de la conquista a la crisis (1238-1350). Valencia, Universitat de València, 2003, p. 104.

63. Furió, Antoni y Garcia-Oliver, Ferran (eds.): Llibre d'establiments i ordinacions de la ciutat de València. I (12961345). Valencia: Publicacions de la Universitat de València, 2007, p. 443.

64. BORDES, Jose: Desarrollo industrial textil y artesanado..., p. 234. 
En cualquier caso, Valencia no es el único caso donde escasean las disposiciones del Consell. Las respectivas ordenaciones municipales de Alcoi y de Cocentaina no recogen ninguna disposición al respecto, pese a la importante presencia del colectivo mudéjar en la región. ${ }^{65}$ Posiblemente, las autoridades no necesitaron legislar a propósito del lino porque este ocupaba un lugar marginal en la economía local. El campesinado local, cristiano y mudéjar, consideraba más rentable otras actividades relacionadas con la ganadería y la agricultura como la obtención de la lana o la producción de aceite. ${ }^{66}$

Si en términos absolutos, el número de disposiciones referidas al lino era más bien escaso, su importancia resulta aún más relativa si cabe comparándola con otras esferas de la producción agrícola y de los intercambios. Tomando como ejemplo el caso de la villa de Gandia, de las Io4 ordenaciones recopiladas en su Llibre d'establiments en el último tercio del siglo XIV, solamente una de ellas tenía que ver con el lino. ${ }^{67}$ Otros asuntos, como la ubicación de las colmenas de abejas, la recolección de leña y carbón o la venda de volatería, requerían de mayor regulación por parte del gobierno local. Esta disposición municipal permitía el macerado del lino únicamente en el tramo final del río de Alcoi y en los estanques de las marjales, bajo pena de 6o s. y perder la materia prima. En el caso de Vila-real, situada al norte del país, la proporción era similar ya que, de las 308 ordenaciones dictadas antes de I50I, solamente 3 estaban relacionadas con el macerado y la transformación del lino. ${ }^{68}$

El caso en el que parece ser que existió una mayor regulación de las actividades de transformación del lino fue la villa de Castellón de la Plana particularmente a lo largo de la segunda mitad del siglo XV. Desde I447, las disposiciones que establecían el macerado del lino en una zona muy concreta del término municipal -en el Estany de l'Obra nova- se repitieron, síntoma de su incumplimiento. La particularidad de este caso es que sabemos que la ingesta por parte de animales de trabajo y de personas de agua en la que había sido tratado el lino a punto estuvo de acarrearles la muerte. ${ }^{69}$

65. Alabau, Jose Antonio: «Els establiments locals com a instrument de control econòmic i social de les viles medievals valencianes. Cocentaina a la darreria del segle XIV», Afers, 47 (2004), pp. 175-187.

66. LLIBRER, Josep Antoni: «Llana, ramat i oli. Empreses en época medieval: nivel d'inversió i costos a la draperia. El comtat al segle XV», Saitabi, 64-65, (2014), pp. 63-79.

67. GARCIA, Ferran (ed.): Llibre d'establiments de Gandia. Imatges i missatges en una vila medieval, Gandia: Arxiu Municipal de Gandia, 1987, establecimiento 66.

68. GIL, Vicent (ed.): Ordenances municipals de Vila-real...

69. IRADIEL, Paulino et al.: Oficios artesanales y comercio en Castelló de la Plana (1371-1527). Castelló de la Plana, Fundación Dávalos Fletcher, 1995, p. 45. 


\section{EL LINO, ¿UNA INDUSTRIA RURAL?}

El lino ha sido considerado una planta industrial en la medida que no era un cultivo destinado al consumo humano y que requería de preparación previa para su ulterior utilización en el sector textil. Es cierto que este proceso de transformación suponía la creación de cierto valor añadido, razones por las cuales cabría la posibilidad de considerar esta fase del hilado como una industria en si misma. Sin embargo, al menos para el caso del reino de Valencia durante la baja edad media y primeros siglos de época moderna, hay que preguntarse hasta qué punto el hilado del lino puede ser calificado de industria rural en el mismo sentido que lo fueron el azúcar, la cerámica, la lana o el cuero. ${ }^{70}$

A diferencia de estos sectores mencionados, la manufactura del lino no comportó una subdivisión del proceso productivo con la consiguiente especialización. Salvo raras excepciones, no existía un artesanado dedicado a la preparación de esta fibra para la ulterior confección de paños, sino que eran los miembros de la familia campesina quienes realizaban las sucesivas fases de transformación. Solamente de forma puntual encontramos algunos individuos especializados en una fase concreta de la preparación del lino, pero se trata de casos aislados. Así, por ejemplo, para la villa de Castellón de la Plana en la baja edad media se documenta un único picador de lli, Pere Sanchis..$^{71}$ Este hecho contrasta con otras regiones de la península Ibérica como la zona de Córdoba, donde sí se constata la presencia de profesionales del sector. ${ }^{72}$

Tanto en la sociedad cristiana como en la musulmana, el hilado y el tejido correspondía a las mujeres mientras que las tareas más físicas como el espadat las realizaban los hombres. En este sentido, el caso de la baronía de Carlet antes expuesto resulta altamente ilustrativo. La producción era, fundamentalmente, de ámbito doméstico y, al menos en parte, destinado al autoconsumo o, en todo caso, al mercado local. Esta vinculación del hilado y posterior tejido con la mujer queda reflejada también en los legados testamentarios. En efecto, tanto las ropas de la casa como las reservas de lino solían ser transmitidas a las hijas por delante de sus hermanos, bien en el momento del casamiento o bien cuando ser realizaba el testamento. El campesino de Cocentaina Guillem Sanç y su mujer Iolant dejaron en su testamento totes les robes de llana e lli que había en la casa donde vívían a su hija Úrsola. ${ }^{73}$ Algunas mujeres, ante la ausencia de hijas, hacían este legado a sus nietas. Así hizo lolant, viuda de Pere Valls de Penàguila, que legó a su nieta, entre

70. Sobre estos productos véase NAVARRO, German: «Los sectores punta de la industria rural en la Corona de Aragón: azúcar, textil y otros» en NAVARRO, German y VILLANUEVA, Concepción: Industrias y mercados rurales..., p. 175-202.

71. IRADIEL, Paulino et al.: Oficios artesanales..., p. 106.

72. Córdoba, Ricardo: La industria medieval..., pp. 92-93.

73. APARISI, Frederic: Del camp a la ciutat..., p. 319. 
otros bienes, totes les robes de lli i tot el lli filat i per filar que se hallare en casa de ella el día de su muerte. ${ }^{74}$

Pero el hilado, contrariamente al cultivo, no se limitaba a los sectores acomodados, sino que abarcaba a todos los segmentos sociales. En aquellos casos que la propia familia no podía asumir el hilado de toda la producción propia se recurría a su venta o a la contratación de mujeres que buscaban obtener así ingresos complementarios. Hay que decir que las referencias a este tipo de compraventas y contrataciones son escasas. Entre las condenas de la corte del justicia, encontramos, de forma aislada, algunos ejemplos debido al incumplimiento del contrato por alguna de las partes. Debido al impago de la media arroba que le había comprado, Mateu Llidó denunció a la mujer de Miquel Gironés ante el justicia de Alcoi, villa de la cual eran todos ellos vecinos. ${ }^{75}$ Hay que tener en cuenta, además, que el hilado entre la sociedad cristiana, no se circunscribía a la esfera campesina. Las mujeres que estaban acogidas en los hospitales, y que su salud se lo permitía, debían ocupar su tiempo hilando lino y estopa, entre otras tareas. ${ }^{76}$ La finalidad de este lino debía ser la confección de ropas y sábanas para los propios centros sanitarios, ya que estas piezas solían degradarse con facilidad.

Por supuesto, el trabajo de hombres y mujeres requería saber del macerado de la planta y el conocimiento del uso del torno, pero estos requerimientos no implican que estemos ante una mano de obra especializada, comparable a otros procesos productivos. El hilado del lino era una más de las actividades que se realizaban al margen de la explotación agrícola con el fin de complementar los ingresos de la familia. Precisamente, el hecho que el trabajo fuera realizado en el espacio doméstico ahonda en esta idea de la complementariedad. Solamente algunas familias acomodadas del campo hicieron del lino una especialización productiva, como los Castrellenes, gestionada mediante mano de obra asalariada. Sin embargo, de ello no se infiere que los jornaleros utilizados en la recolección de la planta y en la hilatura fueran artesanos especializados.

La única mano de obra especializada aparecía finalizado el proceso. Era el teixidor de draps de lli, que adquiría las madejas para la confección de paños en las villas medianas y en la capital del país. También tejían bajo demanda y previa entrega de la materia prima, como hemos visto en el caso de Joan Esparaguera, que entregó a teixir 20 libras de lino para la confección de dos paños. El número de estos tejedores profesionales del lino era ciertamente escaso y disperso, a tenor de las escasas referencias documentales de que disponemos. ${ }^{77}$ Así, por ejemplo, el notario Joan Gamisa, que trabajó en la ciudad de Valencia al menos entre 1475

74. ApARISI, Frederic: Del camp a la ciutat..., p. 290

75. AMA, Cort del Justícia, n. 274, f. 352 (15-III-1454).

76. RodRIGo PertegÀs, Jose: «Hospitales de Valencia en el siglo XV: su administración, régimen interior y condiciones higiénicas», Boletín de la Real Academia de la Historia, 90 (1927), pp. 561-609, concretamente p. 585.

77. También podemos citar el ejemplo de Pere Oliver, texidor de li, vecino de Valencia. En su testamento no hay ninguna referencia de parientes o conocidos dedicados al mismo oficio. ACCV, Protocols, núm. 13.873 (1-XI-1498). 
i I49I solamente recoge una única referencia a un texidor de lli, Jaume Bosc. ${ }^{78}$ Ahora bien, pese a la existencia como hemos visto anteriormente de telares específicos de lino, no habría que descartar la posibilidad que los mismos artesanos que participaban en la confección de paños de lana lo hicieran también con esta fibra de origen vegetal. En cualquier caso, todo ello nos remite, de nuevo, a la idea de una escasa especialización y la falta de concentración de la actividad. Precisamente debido a estas deficiencias, resultaba difícil la estandarización del proceso y de las calidades, con vistas a producir para el mercado. En definitiva, el sector textil del lino, como el del algodón o el cáñamo, mantuvieron a lo largo de los siglos XV y XVI estructuras organizativas y productivas tradicionales. ${ }^{79}$

Sin embargo, el grado de especialización de la mano de obra, la división del proceso productivo y la estandarización de este no son los únicos factores para tener en cuenta a la hora de considerar una actividad como una industria rural. La existencia de un capital comercial resulta esencial para consolidar y ampliar los procesos productivos y de comercialización. Su incidencia se puede apreciar claramente en actividades como el azúcar o la lana. En nuestro caso no detectamos la presencia de agentes que avanzaran capitales o que proveyeran de materia prima a los campesinos para el hilado, si exceptuamos la que entregaban los señores a sus vasallos musulmanes, que procedía de la partición de la cosecha. Fuera de este ámbito, los ejemplos son escasísimos. Así, por ejemplo, el i8 de junio de I54I el campesino de Xàtiva Miquel Candel entregó a una viuda morisca de la Alquería d'en Francesc, situada en la huerta de dicha ciudad, I7 libras de lli filat y otras 4 de cotó filat (...) ad texendum, trabajo por el cual recibiría II s. ${ }^{80}$

Desde el punto de vista de la inversión, tampoco parece que exista paralelismo entre el lino y los otros sectores ya mencionados. Es cierto que aquellas familias campesinas que hacían del manufacturado del lino su principal fuente de ingresos sí que debían afrontar una inversión mayor, particularmente garantizarse la disponibilidad de balsas donde macerar la fibra. Pero para la mayor parte del campesinado que participaba de esta actividad la inversión era realmente modesta. Podían macerar su cosecha en los cursos fluviales o pagar por utilizar las balsas de otros. Y el instrumental, fácilmente se podía adquirir en el mercado de segunda mano cuando no se compraba nuevo. El 25 de septiembre de 1489 fueron vendidos algunos bienes de Pere Montaner para hacer frente a la donación de 400 s. que había hecho el difunto. Entre los distintos objetos,

78. Además, no es el protagonista del acto jurídico registrado por el notario, ya que simplemente figura como referente de su esposa, Joana, que es quien lo protagoniza. ACCV, Protocols, núm 21.515 (20-X-1479).

79. CRuselles, Enrique: «El mercado de telas y 'nuevos paños ligeros' en Valencia a finales del siglo XV», Acta Historica et Archaeologica Medieaevalia, 19 (1998), pp. 245-272, concretamente p. 265.

80. APARISI, Frederic y MUÑOz, Daniel (eds.): Els registres notarials de Miquel Llagària. Sueca, 1541-1552. Valencia, Publicacions de la Universitat de València, 2012, documento 11. 
fueron subastados hun rastel de rastellar lli vell e sotil por $2 \mathrm{~s}$. I d. y aún, un altre rastel vell e sotil por tan solo $8 \mathrm{~d} .^{8 \mathrm{r}}$

Finalmente, una de las características de las industrias rurales fue su impacto sobre el medio natural circundante. En mayor o menor medida, el desarrollo de estas actividades supuso un cambio en el paisaje agrario y en el entorno natural de la zona en la que tuvieron lugar. Un buen ejemplo de ello es la industria del azúcar en la huerta de Gandia que influyó notablemente en el paisaje de la comarca durante los siglos XV-XVIII. Primero porque la difusión del cultivo a lo largo del siglo XV cambió el paisaje agrario de las tierras de regadío. Y ello no solamente por la obligación de los vasallos musulmanes de cultivar, al menos, 2 hanegadas $\left(\mathrm{I} .664 \mathrm{~m}^{2}\right)$ de tierra de regadío, sino también porque, a fin de atender las demandas de agua que necesitaba la planta para su crecimiento, se construyeron nuevas acequias, convirtiendo en regadío tierras que hasta entonces lo habían sido de secano. ${ }^{82}$ Y segundo porque, a fin de atender las necesidades de combustible de los trapiches, se produjo una intensa deforestación de la comarca que obligó a la adquisición de madera de las sierras interiores del Júcar y del Guadalaviar que bajaban por estos ríos hasta la costa. Una vez allí, los troncos eran conducidos por mar hasta las playas de la Safor, donde los vasallos musulmanes, luego moriscos, los recogían y los transportaban hasta los distintos trapiches de la comarca. ${ }^{83}$

Obviamente, no todas las industrias rurales tuvieron un impacto de estas dimensiones sobre su entorno, pero en el caso del lino, nada parece indicar que tuviera una incidencia significativa en el paisaje agrario valenciano. Por el contrario, era uno más de los cultivos que podían introducir los campesinos para complementar sus ingresos de forma voluntaria o, en el caso de los musulmanes, si el señor lo imponía. Así, por ejemplo, mientras que -como hemos visto anteriormente- los vasallos de Benilloba debían entregar cierta cantidad de lino hilada al señor, además de la partición, en el caso de Ares, situada solamente a unos $6,5 \mathrm{~km}$ de distancia, no hay ningún tipo de requerimiento al respecto por parte de la señoría. ${ }^{84}$ No se puede decir, por tanto, que el lino fuera un cultivo común en esta comarca. Pero incluso desde la perspectiva de la economía local, hay que matizar su importancia. El lino en Benilloba tributaba la misma cantidad que los cereales, los higos y las legumbres, I/3 de la cosecha. Por contra, la partición del aceite era al 50\% y, además, el vasallo debía entregar un cadaf (aproximadamente, I,375 1.) de aceite común por cada cahiz (20I 1.) de las aceitunas que no fueran molidas en la almàssera o molino de aceite. Por tanto, según

\footnotetext{
81. Idem, núm. 23.010 (25-IX-1489).

82. ESQUILACHE, Ferran y APARISI, Frederic: Aigua per al pa, aigua per al sucre. La construcció de la Sèquia d'en March i de Palma a l'Horta de Gandia. Segles XIII-XV. Lleida, Publicacions de la Universitat de Lleida, 2019, pp. 50-62.

83. Valga como ejemplo la adquisición de 1.200 quintares lignorum de tota lenya, unos 50.000 kg., que hizo Guillem Ramon Pujades para su trapiche de Piles el 1499. El precio de la compra, que no fue la única aquel año, ascendía a los 3.024 sueldos. ACCV, Protocols, núm. 13.878 (23-II-1499).

84. Idem, núm. 23.808 (21-IV-1485).
} 
se desprende del arrendamiento mencionado, el paisaje agrario de Benilloba era bastante diverso, aunque si había un cultivo con un papel central y básico en la economía local, éste era el olivo, como en el cercano Ares y en la mayor parte de las comarcas centrales valencianas. ${ }^{85}$

\section{A MODO DE CONCLUSIÓN}

El examen detenido de diversas tipologías documentales permite constatar que el cultivo y la producción de lino en el reino de Valencia formó parte de las estrategias productivas del campesinado tanto cristiano como musulmán. De la producción mudéjar tenemos constancia gracias a las cartas de población que les obligaban a la entrega de cierta cantidad hilada de lino, además de una parte de la producción. De esta manera, el señor obtenía unos ingresos que si bien no eran importantes no estaban de más en las siempre escasas rentas de la pequeña nobleza valenciana. Los vasallos cristianos no estaban sometidos a estas imposiciones, pero sí que tenían que hacer frente a las particiones de la cosecha. En cualquier caso, más que las cartas de población, lo que nos informa de la producción entre el campesinado cristiano son las obligaciones ante la Corte de justicia y los inventarios de bienes consignados por el notario.

A través de estas fuentes podemos concretar que el principal ámbito del hilado fue el doméstico mediante el trabajo de las mujeres de la familia. No se detecta, salvo alguna excepción, la existencia de una mano de obra especializada y asalariada, al margen de las imposiciones feudales, sino que más bien se trata de un saber agrario o un conocimiento experto propio de las gentes del campo como lo era el mantenimiento de las infraestructuras de riego o la poda de los árboles. La ausencia tanto de una mano de obra especializada, así como del capital comercial y el escaso impacto sobre el medio natural lleva a preguntarnos hasta qué punto resulta pertinente referirse al procesado del lino como una industria rural. En efecto, más que ante una industria rural como la del azúcar o el carbón, en el caso del lino estamos ante uno más de los trabajos complementarios de la explotación campesina. Como la trajinería o la recolección de determinadas plantas silvestres, también el trabajo del lino requiere de una expertise para la obtención de resultados satisfactorios pero la necesidad de conocer la técnica no conlleva necesariamente el carácter de industrial de esta actividad.

Podemos concluir, por tanto, que, sin especialización productiva, estandarización del producto, participación del capital comercial y tampoco un impacto sobre el entorno natural resulta difícil de concebir el procesado del lino y el posterior hilado como una industria rural propiamente dicha, al contrario que otras fibras

85. APARISI, Frederic: Del camp a la ciutat..., p. 69 
textiles como la lana o la seda. Ello no es óbice para que estas actividades no tuvieran importancia en las economías domésticas del campesinado. Se trataba de una actividad que permitía obtener unos ingresos al margen de las tareas agrícolas gracias a la implicación de las mujeres de la familia. Pero en el caso del campesinado musulmán era, también, una obligación impuesta por los señores. La pretendida especialización, en todo caso, era forzada. 


\section{BIBLIOGRAFIA}

\section{FUENTES EDITADAS}

Aparisı, Frederic y MuÑoz, Daniel (eds.): Els registres notarials de Miquel Llagària. Sueca, I54I-I552. Valencia, Publicacions de la Universitat de València, 2012.

Ardit, Manuel y Guinot, Enric (eds.): Cartes de poblament modernes valencianes (XVI-XVIII). Valencia, Publicacions de la Universitat de València, 2015.

Febrer Romaguera, Manuel (ed.): Les aljames mudèjars valencianes en el segle XV. Valencia, Publicacions de la Universitat de València, 2006.

FURIó, Antoni y GARCIA-Oliver, Ferran (eds.): Llibre d'establiments i ordinacions de la ciutat de València. I (I296-I345). Valencia: Publicacions de la Universitat de València, 2007.

GARCIA, Ferran (ed.): Llibre d'establiments de Gandia. Imatges i missatges en una vila medieval, Gandia: Arxiu Municipal de Gandia, I987.

Gil, Vicent (ed.): Ordenances municipals de Vila-real (segles XIV-XVIII). Valencia: Publicacions de la Universitat de València, 2002.

Guinot, Enric (ed.): Cartes de poblament medievals valencianes, Valencia, Generalitat Valenciana, I99I.

LAIRON, Aureliano (ed.): Libre de diverses statuts e ordinacions fets per lo consell de la vila de Algezira. Valencia: Publicacions de la Universitat de València, 200I.

\section{PUBLICACIONES}

AlabaU, Jose Antonio: «Els establiments locals com a instrument de control econòmic i social de les viles medievals valencianes. Cocentaina a la darreria del segle XIV», Afers, 47 (2004), pp. I75-I87.

AlAPONT, Llorenç: «El mundo funerario en el limes visigodo-bizantino: el territorio valenciano», Gausac. Contextos funeraris a la Mediterrània nord-occidental, 34-35, (2009), pp. I45-158.

Albiach Descals, Rosa y Madaria, José Luis: La villa de Cornelius. Valencia, 2006.

ANDRÉS VALERO, Sebastián: «El campesinado en Aragón en el reinado de Jaime I (I2I3-I276)» en SARASA, Esteban: La sociedad en Aragón y Cataluña en el reinado de Jaime I (I213-I276). Zaragoza, Institución Fernando el Católico, 2009.

ApARICI, Joaquím: «Bienes muebles de mudéjares castellonenses. Siglo XV», Sharq alAndalus, I9, (2008-2010), pp. 69-90.

ApARICI, Joaquím: «Capilaridad de la manufactura textil en la plana de Castelló. El caso de Onda en el siglo XV», Anuario de Estudios Medievales, 40-I, (2010), pp. I8I-I99.

APARICI, Joaquím: «Acudir ante el justicia para formalizar contratos. Los mercados rurales del norte del reino de Valencia (siglo XV)» en Navarro, German y VillanueVa, Concepción: Industrias y mercados rurales en los reinos hispánicos (siglos XIII-XV). Murcia, Sociedad Española de Estudios Medievales, 2017.

APARISI, Frederic: Del camp a la ciutat. Les elits rurals valencianes a la baixa edad mitjana, (Tesis doctoral inédita), Universitat de València, 2016. 
Benito, Pere: Senyoria de la terra i tinença pagesa al comtat de Barcelona (segles XI-XIII). Barcelona, CSIC, 2003.

Bolens, Lucien: Agronomes andalous du moyen âge. París, Droz, I98I.

BORDES, Jose: Desarrollo industrial textil y artesanado en Valencia de la conquista a la crisis (I238-I350). Valencia, Universitat de València, 2003.

Córdoba, Ricardo: La industria medieval de Córdoba. Córdoba, Caja Provincial de Ahorros, I990.

Córdoba, Ricardo: «Industria y artesanía rural en la Corona de Castilla a finales de la Edad Media» en Navarro, German y Villanueva, Concepción: Industrias y mercados rurales en los reinos hispánicos (siglos XIII-XV). Murcia, Sociedad Española de Estudios Medievales, 2017, p. 37-62.

CRuselles, Enrique: «Pastos, ganadería ovina y mercado regional de la lana en el reino medieval de Valencia» en Mattone, Antonio y Simbula, Pinuccia: La pastorizia mediterranea. Storia e diritto, secoli XI-XX. Roma, Carocci, $201 \mathrm{~s}$.

CRUSELles, Enrique: «El mercado de telas y 'nuevos paños ligeros' en Valencia a finales del siglo XV», Acta Historica et Archaeologica Medieaevalia, I9 (I998), pp. 245-272.

ESQUILACHE, Ferran y APARISI, Frederic: Aigua per al pa, aigua per al sucre. La construcció de la Sèquia d'en March i de Palma a l'Horta de Gandia. Segles XIII-XV. Lleida, Publicacions de la Universitat de Lleida, 2019.

FERRAGUd, Carmel: El naixement d'una vila rural valenciana. Cocentaina, I245-1304. Valencia, Publicacions de la Universitat de València, 2003.

Garcia-Oliver, Ferran: La vall de les sis mesquites. El treball i la vida a la Valldigna medieval. Valencia, Publicacions de la Universitat de València, 2003.

Garcia-Oliver, Ferran: «Élites campesinas en el entorno de la ciudad de Valencia: los Castrellenes», Studia histórica. Historia medieval, 35-2, (2017), pp. II9-I44.

Guinot, Enric: «Los mudéjares de la Valencia medieval: renta y señorío», Áreas, I4, (I992), pp. 29-47.

Hinojosa, Jose: Los mudéjares. La voz del Islam en la España cristiana. Teruel, Centro de Estudios Mudéjares, 2002.

IguAL, David et al.: «Materias primas y manufacturas textiles en las aljamas rurales valencianas» en VI Simposio Internacional de Mudejarismo. Teruel: Centro de Estudios Mudéjares, 1996.

IRADiel, Paulino et al.: Oficios artesanales y comercio en Castelló de la Plana (I37I-I527). Castelló de la Plana, Fundación Dávalos Fletcher, I995.

LA PARra, Santiago: Los Borja y los moriscos. Repobladores y terratenientes en la Huerta de Gandía tras la expulsión de I609, Valencia, Institució Alfons el Magnànim, I992.

LAGARDERE, Vincent: «(I99I). Culture et industrie du lin en al-Andalus», Studia Islamica, LXXIV, (I99I), pp. I43-I65.

LOMbARD, Maurice: Les textiles dans le monde musulman VII-XII siècle. París, Mounton, 1978.

LLIBRER, Josep Antoni: «Llana, ramat i oli. Empreses en época medieval: nivel d'inversió i costos a la draperia. El comtat al segle XV», Saitabi, 64-65, (2014), pp. 63-79.

Mira JodAr, Antonio José: Entre la renta y el impuesto. Fiscalidad, finanzas y crecimiento económico en las villas reales del sur valenciano (siglos XIV-XV). Valencia, Publicacions de la Universitat de València, 2005.

NAVARro, German: Industria y artesanado en Valencia, I450-I525: las manufacturas de seda, lino cáñamo y algodón, (Tesis doctoral), Universitat de València, I995.

NAVARro, German: «Los sectores punta de la industria rural en la Corona de Aragón: azúcar, textil y otros» en Navarro, German y Villanueva, Concepción: Industrias y 
mercados rurales en los reinos hispánicos (siglos XIII-XV). Murcia, Sociedad Española de Estudios Medievales, 2017, p. 175-202.

NAvArro, Joaquín: Bocairent Geografia i historia. Bocairent, Ajuntament, 2004 (Original publicado en i923).

PAStor, Manel: Les senyories valencianes dels comtes d'Urgell. Les baronies de Bunyol, Xiva i Xestalgar entre el I238 i el I327: renda i jurisdicció, (Tesis doctoral inédita), Universitat de València, 2015.

PıQUeras, Juan: «El fomento de plantas textiles en la España ilustrada. Una visión espacial», Cuadernos de geografía, 50 (I99I), pp. 247-262.

Rodrigo Pertegàs, Jose: «Hospitales de Valencia en el siglo XV: su administración, régimen interior y condiciones higiénicas», Boletín de la Real Academia de la Historia, 90 (I927), pp. 56I-609.

TORRó, Josep: El naixement d’una colónia. Dominació i resistència a la frontera valenciana (I238-I276). Valencia, Publicacions de la Universitat de València, 2006.

TorRó, Josep: «Del almagram a las particiones de frutos. Las cargas agrarias en las aljamas musulmanas del reino de Valencia» en VALLEJO, Rafael: Los tributos de la tierra. Fiscalidad y agricultura en España (siglos XII-XX). Valencia, Publicacions de la Universitat de València, 2008.

TorRó, Josep: «Vivir como cristianos y pagar como moros: genealogía medieval de la servidumbre morisca en el reino de Valencia», Revista de historia moderna: Anales de la Universidad de Alicante, 27 (2009), pp. II-40.

VAllvé Bermejo, Joaquín: «La industria en al-Ándalus», Al-Qantara, I (I980), pp. 209-24I.

Viciano, Pau: «Pagesos que innoven. La petita explotació en les transformacions agràries de la fi de l'edat mitjana» en BARCEló, Miquel et al.: El feudalisme comptat i debatut. Formació i expansió del feudalisme català. Valencia, Publicacions de la Universitat de València, 2003.

Viciano, Pau: Els peus que calciguen la terra. Els llauradors del País Valencià a la fi de l'edat mitjana. Valencia, Publicacions de la Universitat de València, 2012. 
Calidad de Revistas

Científicas Españolas

FECYT |
SERIE III HISTORIA MEDIEVAL

REVISTA DE LA FACULTAD DE GEOGRAFÍA E HISTORIA
AÑO 2020

ISSN: 0214-9745

E-ISSN 2340-1362

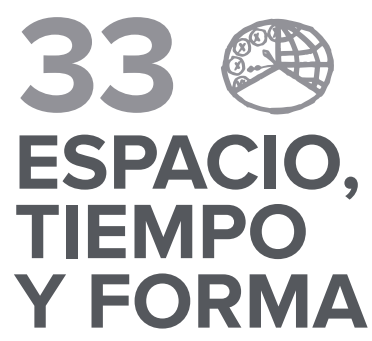

\section{Artículos · Articles}

7 FREDERIC APARISI ROMERO

El cultivo y procesado del lino en el Reino de Valencia (ss. XIII-XVII)

13 ADRIÁN CALONGE MIRANDA

El mantenimiento del entramado viario romano en época medieval en La Rioja. Algunos casos de estudio

\section{Miguel Calleja Puerta}

Notarios públicos entre dos reinos. Apuntes diplomáticos sobre documentos notariales castellanos en el Arquivo Distrital de Braga

\section{Xavier Casassas Canals}

Las 'aqida-s entre los musulmanes castellanos y aragoneses de época mudéjar y morisca: Las 'aqĩda-s de Ibn Abi Zayd Al-Qayrawāni (s. X), Ibn Tümart (s. XII) e Isa de Jebir (s. XV)

\section{ARCADIO DEL CASTILLO}

Sobre el Códice Alcobacense de Vaseo y los Annales Portugalenses Veteres: Continuidad del reino visigodo de Toledo

\section{Paula Castillo}

Las formas de la violencia entre frailes. El testimonio de Fray Ubertino de Casale

\section{María Eugenia CONTRERAS JIMÉnEZ}

La memoria del linaje Arias Dávila en la cofradía y hospital de San Cosme y San Damián de Valladolid (siglos XV a XVII)

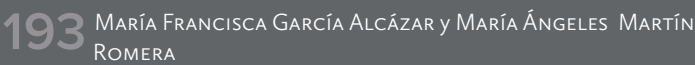
Entre servicio regio y estrategia personal: Los Continos de Valladolid (1480-1525)

\section{César García de Castro Valdés y josé Antonio Valdés
Gallego}

Las inscripciones perdidas de la basílica altomedieval de San Salvador de Oviedo

\section{María José Lop OtÍN}

Hay tal número de clérigos que causa asombro. La clerecía de Toledo a fines de la Edad Media

\section{CORINA LUCHÍA}

Por que los montes de esta villa se conserben, e no se disipen como al presente estan: La regulación de los recursos forestales en la Corona de Castilla (siglos XIV-XVI)
333 María Encarnación Martín López

Las inscripciones medievales del claustro de la catedral de Roda de Isábena (Huesca). Aproximación a su taller lapidario

\section{ISABEL MONTES ROMERO-CAMACHO}

Los archivos catedralicios y su importancia para los estudios prosopográficos. El deán Don Aparicio Sánchez, en el Archivo de la Catedral de Sevilla

\subsection{Gonzalo Oliva Manso}

La moneda en Castilla y León (1265-1284). Alfonso X, un adelantado a su tiempo.

4.73 Mariana Valeria Parma

Entre los signos del cielo y las voces de los hombres: La visión medieval del cielo y su representación apocalíptica

\section{Milagros Plaza Pedroche \\ Los maestres santiaguistas y su designación regia durante el} reinado de Juan I de Trastámara (1379-1390): La legitimación del proceso

521 Juan A. Prieto Sayagués

La profesión de las élites castellanas en los monasterios y conventos durante la Baja Edad Media

\section{EnRIQUe José RuIz PILARES}

La funcionalidad social de los inmuebles urbanos de las élites dirigentes bajomedievales: Reflexiones a partir de un caso de estudio (Jerez de la Frontera, España)

\section{Gilberto SORIANO Calvo}

Influencia de las redes nobiliarias en la expansión cristiana del siglo XII. El caso de Soria

Mohammed S. TawfiQ, AlmudenaArizaArmada, Atef Mansour Mohammad, Ahmed Ameen y Mervat Abd EL-HadyAbdEL-Latif A Historical and Numismatic Study of the Dinars of the Ghaznavid Sultan Mahmūd B. Sabuktakin at Nishapur

653 JOSÉ LUIS DE VILLAR IGLESIAS

Los aspectos económicos en la Batalla por el Magreb entre omeyas y fātimíes: El control del acceso al oro del Sudán Occidental

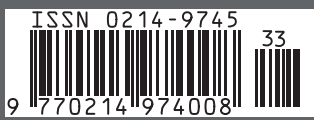




\section{3}

\section{ESPACIO,}

\section{TIEMPO}

Y FORMA

UกED

SERIE III HISTORIA MEDIEVAL

REVISTA DE LA FACULTAD DE GEOGRAFÍA E HISTORIA

\section{Libros · Books}

679 Bello León, Juan Manuel y ORTEgo Rico, Pablo, Los agentes fiscales en la Andalucía Atlántica a finales de la Edad Media: Materiales de trabajo y propuesta de estudio (ANA MARÍA RIVERA MEDINA)

683 Calleja Puerta, Miguel y Domínguez Guerrero, María Luisa (eds.), Escritura, notariado y espacio urbano en la Corona de Castilla y Portugal (siglos XII-XVII) (PALOMA CUENCA MuÑoz)

687 CASADO ALONSO, Hilario (coord.), Comercio, finanzas $y$ fiscalidad en Castilla (siglos XV-XVI) (ANA MARía RIVERA MEdINA)

691 Castro Correa, Ainoa y Rodríguez Sánchez, Manuel, Colección diplomática altomedieval de Galicia II. Documentación en escritura visigótica de la sede lucense (PALOMA CUENCA MUÑOZ)

695 García Fernández, Ernesto, García-Gómez, Ismael, Rodríguez FERNÁNDEZ, José, Urbanismo, patrimonio, riqueza y poder en Vitoria-Gasteiz a fines de la Edad Media e inicios de la Edad Moderna (ENRIQUE CANTERA MONTENEGRO)

699 LADERO QUESADA, Miguel Ángel, Ciudades de la España medieval. Introducción a su estudio (GISELA CORONADO SCHWINDT)

705 LADERo Quesada, Miguel Ángel, Los últimos años de Fernando el Católico 1505-1517 (CARLOS BARQuero GoÑI)

707 Martín GutiérRez, Emilio y Ruiz Pilares, Enrique José, El viñedo en Jerez durante el siglo XV. Un mercado de trabajo en torno al vino (ANa María Rivera MEDINA)

711 MONSALVO ANTÓN, José María, La construcción del poder real en la monarquía castellana (siglos XI-XV) (MARÍA Jesús FUENTE)

715 Pérez Rodríguez, Francisco Javier, Los monasterios del Reino de Galicia entre 1075 y 1540: De la reforma gregoriana a la observante (EnRIQue CANTERA Montenegro)

717 REIXACH SALA, Albert, Finances públiques i mobilitat social a la Catalunya de la Baixa Edat Mitjana. Girona, 1340-1440 (JuLIÁN DONADO VARA)

721 SÁNCHEZ SÁNCHEZ, Xosé M., Iglesia, mentalidad y vida cotidiana en la Compostela medieval (ENRIQUe CANTERA MONTENEGRO)

725 Val Valdivieso, M. ${ }^{a}$ Isabel del, Martín Cea y Juan Carlos, CARVAJAL de La Vega, David (coords.), Expresiones del poder en la Edad Media. Homenaje al profesor Juan Antonio Bonachía Hernando (José RAMÓN DÍAZ DE DURANA ORTIZ DE URBINA) 